\title{
Tracheal regeneration: Evidence of bone marrow mesenchymal stem cell involvement
}

\author{
Agathe Seguin, MD, PhD, ${ }^{\mathrm{a}, \mathrm{b}, \mathrm{c}}$ Sonia Baccari, MD, ${ }^{\mathrm{a}, \mathrm{c}}$ Muriel Holder-Espinasse, $\mathrm{MD}, \mathrm{PhD},{ }^{\mathrm{d}}$ \\ Patrick Bruneval, MD, ${ }^{\mathrm{e}}$ Alain Carpentier, MD, ${ }^{\mathrm{a}}$ Doris A. Taylor, $\mathrm{PhD},{ }^{\mathrm{c}}$ and Emmanuel Martinod, MD, $\mathrm{PhD}{ }^{\mathrm{a}, \mathrm{b}}$
}

Objectives: Recent advances in airway transplantation have shown the ability of ex vivo or in vivo tracheal regeneration with bioengineered conduits or biological substitutes, respectively. Previously, we established a process of in vivo-guided tracheal regeneration using vascular allografts as a biological scaffold. We theorized that tracheal healing was the consequence of a mixed phenomenon associating tracheal contraction and regeneration. The aim of the present study was to determine the role that bone marrow stem cells play in that regenerative process.

Methods: Three groups of 12 rabbits underwent a gender-mismatched aortic graft transplantation after tracheal resection. The first group received no cells (control group), the second group had previously received autologous green fluorescent protein-labeled mesenchymal stem cell transplantation, and the third group received 3 labeled mesenchymal stem cell injections on postoperative days 0,10 , and 21 .

Results: The clinical results were impaired by stent complications (obstruction or migration), but no anastomotic leakage, dehiscence, or stenosis was observed. The rabbits were killed, and the trachea was excised for analysis at 1 to 18 months after tracheal replacement. In all 3 groups, microscopic examination showed an integrated aortic graft lined by metaplastic epithelium. By 12 months, immature cartilage was detected among disorganized elastic fibers. Positive SRY gene detection served as evidence for engraftment of cells derived from the male recipient. EF-green fluorescent protein detection showed bone marrow-derived mesenchymal stem cell involvement.

Conclusions: The results of the present study imply a role for bone marrow stem cells in tracheal regeneration after aortic allografting. Studies are necessary to identify the local and systemic factors stimulating that regenerative process. (J Thorac Cardiovasc Surg 2013;145:1297-304)

\section{Supplemental material is available online.}

\footnotetext{
From the University of Paris Descartes, ${ }^{\mathrm{a}}$ Alain Carpentier Foundation, EA Laboratory of Surgical Research, Assistance Publique-Hôpitaux de Paris, European Georges Pompidou Hospital, Paris, France; Department of Oncological Specialties, ${ }^{\text {b }}$ Thoracic and Vascular Surgery Unit, Faculty of Medicine SMBH, Assistance Publique, Hôpitaux de Paris, CHU Paris, Seine Saint Denis, Avicenne Hospital, Paris 13 University, Bobigny, Paris, France; Center for Cardiovascular Repair, ${ }^{\mathrm{c}}$ Department of Integrative Biology and Physiology, University of Minnesota, Minneapolis, Minn; CNRS UMR $8161,{ }^{\mathrm{d}}$ Biological Institute of Lille, University of Lille Nord de France, Pasteur Institute of Lille/FR142, Lille, France; and Department of Anatomopathology, ${ }^{\mathrm{e}}$ Assistance Publique-Hôpitaux de Paris, European Georges Pompidou Hospital, University of Paris Descartes, Medical Faculty of Paris, Paris, France.

This work was supported by funding from the "Fondation Alain Carpentier" (France), the Center for Cardiovascular Repair (University of Minnesota), and the ADETEC Association (France). It was also supported in part by the Medtronic Foundation and the National Institutes of Health Safety and Efficacy of Cellular Cardiomyoplasty (grant 2R01HL063346).

Disclosures: Authors have nothing to disclose with regard to commercial support.

A.C., D.A.T., and E.M. were co-directors of the study.

Received for publication June 29, 2012; revisions received Aug 28, 2012; accepted for publication Sept 20, 2012; available ahead of print Oct 29, 2012.

Address for reprints: Agathe Seguin, MD, PhD, Pôle Spécialités Cancérologiques, Département de Chirurgie Thoracique, Vasculaire, ORL et Stomatologie, Hôpital Avicenne, Hôpitaux Universitaires Seine St Denis, UFR SMBH, Bobigny, Université Paris XIII, 125 rue de Stalingrad, Bobigny 93009 Cedex, France (E-mail: agathe.seguin@avc.aphp.fr).

$0022-5223 / \$ 36.00$

Copyright $\odot 2013$ by The American Association for Thoracic Surgery

http://dx.doi.org/10.1016/j.jtcvs.2012.09.079
}

Most organs are transplantable, but airway transplantation remains an exception, in large part because of the complexity of the structure, the lack of a viable scaffold, and a need for continuous patency. To date, few have overcome these many hurdles to tracheal replacement. ${ }^{1-3}$ As recognized by Bader and Macchiarini, ${ }^{4}$ who transplanted the first tissueengineered trachea in 2008: "Currently, engineering a 3D [3-dimensional] construct such as a trachea or other tissues is complicated not only from the cell biology point of view: the organizational efforts of tissue engineering are indeed formidable." One potential solution to this is in vivo-guided tissue regeneration or rebuilding the trachea in situ. Doing so, likewise requires a transplantable scaffold and appropriate cells for cartilage reconstruction and an epithelial lining.

Previously, we reported that an aortic allograft segment could be a valuable tracheal scaffold in a sheep model..$^{5-7}$ More recently, these results have been confirmed in a pig model. ${ }^{89}$ In those studies, we observed a reepithelialization of the graft and newly formed rings of cartilage, consistent with tracheal regeneration. Hypothesizing the participation of recipient stem cells in the regeneration of a patent, cartilaginous, lined construct, we scaled down to a rabbit model, which was easier to work with for technical reasons, to assess whether bone marrow-derived mesenchymal stem cells (MSCs) were involved. To test this, we transplanted autologous-labeled MSCs to verify bone marrow involvement or injected autologous labeled MSCs 


\section{Abbreviations and Acronyms \\ $\mathrm{GFP}=$ green fluorescent protein \\ MSCs $=$ mesenchymal stem cells \\ PBS = phosphate-buffered saline \\ $\mathrm{PCR}=$ polymerase chain reaction}

intravenously to identify other mesenchymal sources. All rabbits underwent tracheal replacement by aortic allograft as previously described. ${ }^{5-7}$ The labeled cells were therefore tracked in the allograft after explantation.

\section{METHODS}

Gender-mismatched tracheal replacement with a fresh female aortic allograft was performed on 34 male New Zealand white adult-size rabbits. All experiments were conducted in accordance with the Guide for the Care and Use of Laboratory Animals (National Institutes of Health publication no. 86-23, revised 1996) and under study protocols approved by the Institutional Animal Care and Use Committee at the University of Minnesota.

\section{Experimental Design}

The rabbits were assigned to 1 of the 3 following groups: group 1, tracheal replacement alone $(\mathrm{n}=12)$; group 2, autologous green fluorescent protein (GFP)-labeled MSC transplantation and tracheal replacement 3 months later $(\mathrm{n}=12)$; and group 3, tracheal replacement and autologous GFP-labeled MSC injections on postoperative days 0,10 , and $21(\mathrm{n}=12)$.

\section{Cell Culture}

Autologous bone marrow harvest and stem cell culture. Under anesthesia, bone marrow was harvested from the iliac crest. The aspirate was centrifuged, bone marrow mononuclear cells isolated, and red blood cells destroyed using red blood cell lysis buffer. After suspension and washing with phosphate-buffered saline (PBS), the cells were cultured in LTC media containing $\alpha$-minimum essential medium (Invitrogen, Carlsbad, Calif), 12,5\% horse serum (Invitrogen), 12,5\% fetal bovine serum (Hyclone, Logan, Utah), $1 \mu \mathrm{M}$ hydrocortisone (Sigma-Aldrich, St. Louis, Mo), $5 \mu \mathrm{M} \beta$-mercaptoethanol (Invitrogen), $50 \mathrm{U} / \mu \mathrm{g}$ penicillin/streptomycin (Invitrogen), and $0.25 \mu \mathrm{g} / \mathrm{mL}$ amphotericin B (Invitrogen). Nonadherent cells were removed by washing at 48 hours; adherent cells were cultured, with the medium replaced every 2 days. After 15 days of primary culture, individual colonies had formed. When $80 \%$ confluence of cells was achieved, the cells were trypsinized and passaged every 5 days. During the culture period, no cell morphologic alteration occurred. Typical primary or passaged MSCs displayed fibroblast-like morphologic features. The MSCs were positive for CD29 but negative for CD45.

Retroviral vector, virus production, and transfection of MSCs. Recombinant lentiviruses expressing GFP were generated using the 3-plasmid system by cotransfection of 293T cells. Then, MSCs were exposed to viral supernatant containing EF-GFP virus (titer used $1 \times 10^{6}$ transducing units needed $/ \mathrm{mL}$ ) in the presence of $8 \mu \mathrm{g} / \mathrm{mL}$ polybrene for 24 hours, as described by Cui and colleagues. ${ }^{10}$ GFP expression was verified visibly and using quantitative reverse transcriptase polymerase chain reaction (PCR).

MSC transplantation or injection. Rabbits in the MSC transplant group (group 2) received a bone marrow transplantation of labeled MSCs. The rabbits were anesthetized and received sublethal whole body irradiation $(6 \mathrm{~Gy})$ to ablate the native bone marrow. At day 1 after radiation, GFP-labeled autologous MSCs were delivered by ear vein injection. The rabbits were kept under specific pathogen-free conditions. All transplanted rabbits were given enrofloxacin daily during the aplasia period and human granulocyte colony-stimulating factor for 14 days. Complete blood counts, including platelets, reticulocytes, and differential blood counts, were obtained weekly to assess whether the bone marrow had regenerated.

The rabbits receiving autologous MSC injections (group 3) had the labeled cells delivered intravenously at the end of the aortic implant procedure by the ear vein without previous irradiation. The injections were repeated on postoperative days 10 and 21 .

\section{Anesthesia, Surgical Procedure, and Follow-up}

Aortic graft harvest. Descending aortic grafts were obtained from the euthanized rabbits under sterile surgical conditions. Matching of blood and tissue compatibility between the recipient and donor was not attempted. As can be appreciated, the grafts lacked rigid structure and were cartilage free (Figure 1).

Graft interposition. Under anesthesia (intramuscular ketamine 35 $\mathrm{mg} / \mathrm{kg}$ and intramuscular xylazine $10 \mathrm{mg} / \mathrm{kg}$ ), the cervical trachea was dissected through a median cervicotomy (Figure 1). Additional local anesthetic (lidocaine, solution $2 \%, 1 \mathrm{~mL}$ subcutaneously) was injected, keeping the rabbit under spontaneous ventilation. A $1.5-\mathrm{cm}$ tracheal segment was resected and replaced with the aortic allograft supported by a silicone stent $(2.5 \mathrm{~cm}$ long and $5 \mathrm{~mm}$ in diameter; Tracheobronxane Dumon, Novatech, La Ciotat, France). Proximal and distal end-to-end anastomoses were made with a 8-0 polypropylene separate stitch suture (Prolene, Ethicon Endo-Surgery, Blue Ash, Ohio). The stent was secured with additional sutures, and the cervical incision was closed.

Follow-up. Buprenorphine $(0.05 \mathrm{mg} / \mathrm{kg}$, subcutaneously, $2 \times 24$ hours) was administered for the first 48 hours postoperatively and enrofloxacin $(10 \mathrm{mg} / \mathrm{kg}$, intramuscularly, $2 \times 24$ hours $)$ for 10 days postoperatively. Clinical evaluation was performed daily. No immunosuppressive therapy was administered.

\section{Tracheal Collection and Histologic Evaluation}

Death was scheduled at $1,3,6,9,12,15$, and 18 months to explant the grafts. En bloc resection of the trachea with surrounding tissues was performed. After removal of the stent, the postmortem specimens were immediately placed in a $10 \%$ formaldehyde solution. Fixed specimens were embedded in paraffin and cut into $4-\mu \mathrm{m}$ sections, which were stained with hematoxylin-eosin-saffron and orcein. All dead rabbits encountered during the follow-up period or between the euthanasia schedule underwent a postmortem with macroscopic and microscopic examinations.

\section{In Situ Hybridization}

GFP in situ hybridization. Slides from the MSC injection group and MSC transplantation group were analyzed at 1.5, 6, 9, and 15 months after graft implantation and at 3 weeks and 15 months, respectively.

Digoxigenin-11-UTP-labeled single-strand RNA probes were prepared using a DIG RNA labeling kit (Roche Applied Science, Indianapolis, Ind) according to the manufacturer's instructions. GFP cDNA was obtained by PCR amplification using phosphorylated enhanced GFP plasmid (Clontech Laboratories, Mountain View, Calif) as a template and with appropriate primers (5'GGATCCACCGGTCGCCACCAT3' and 5'TCACGTTCTG GAGCAGGACCA3'). Next, the GFP PCR product was cloned in PCRII TOPO plasmid (Invitrogen) and used to generate antisense and sense probes. After deparaffinization, the sections were treated with $10 \mu \mathrm{g} / \mathrm{mL}$ of proteinase $\mathrm{K}$ for 15 minutes at room temperature and subjected to $0.2 \mathrm{~N} \mathrm{HCl}$ to inactivate endogenous alkaline phosphatase. Hybridization was then performed at $50^{\circ} \mathrm{C}$ in $50 \%$ formamide, and washes were performed at a stringency of $2 \times$ saline sodium citrate buffer containing $50 \%$ formamide at $55^{\circ} \mathrm{C}$. Next, the slides were subjected to $10 \mu \mathrm{g} / \mathrm{mL}$ RNase A in TNE (10 mM Tris- $\mathrm{HCl}, \mathrm{pH} 8.0,500 \mathrm{mM} \mathrm{NaCl}$, and $1 \mathrm{mM}$ 


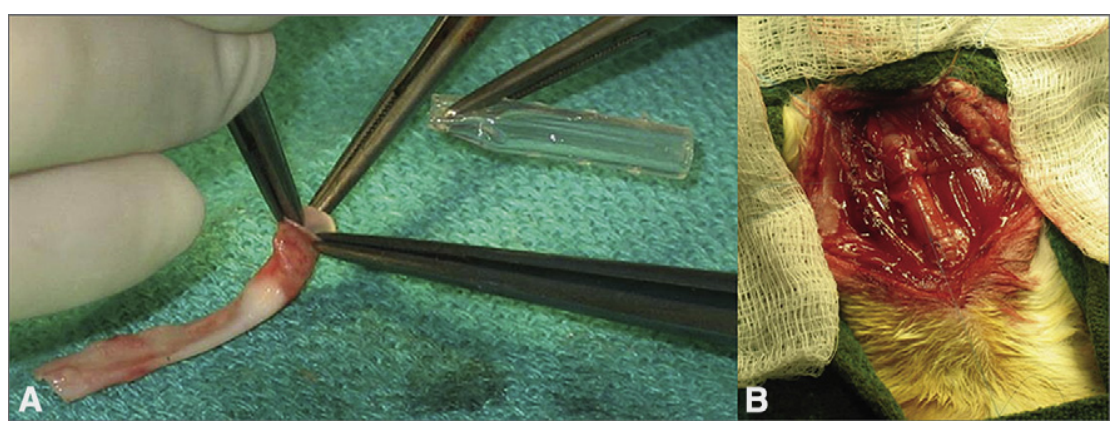

FIGURE 1. Perioperative view showing (A) stent insertion and (B) graft implantation.

ethylenediaminetetraacetic acid) at $37^{\circ} \mathrm{C}$ for 30 minutes for digestion of nonhybridized transcripts and washed. The samples were incubated overnight with anti-Dig-alkaline phosphatase. We detected the Dig probe with nitro-blue tetrazolium chloride/5-bromo-4-chloro-3'-indolyphosphate p-toluidine salt as a substrate to give a purple/blue color. We stopped the reaction with 3 changes of a buffer containing $1 \mathrm{mM}$ ethylenediaminetetraacetic acid, fixed the samples with $4 \%$ paraformaldehyde $/ 0.2 \%$ glutaraldehyde. These samples were mounted with Dakocytomation glycergel (Dakocytomation, Milan, Italy) and observed under a Zeiss Axioplan 2 microscope (Carl Zeiss, le Pecq, France)

Chromosome $\mathbf{Y}$ fluorescence in situ hybridization on paraffin-embedded tissue sections. Identification of cells in the sex-mismatched grafts was studied using Y chromosome fluorescence in situ hybridization. This technique was performed on slides from the MSC injection group at 6 and 9 months.

The STAR*FISH rabbit Y chromosome-specific paint (Cambio, Cambridge, United Kingdom) was used according to the manufacturer's instructions. Tissue sections were deparaffinized in toluene and rehydrated in a $100 \%, 95 \%, 70 \%$, and $50 \%$ ethanol series, incubated with a sodium thiocyanate solution for 10 minutes at $80^{\circ} \mathrm{C}$, and then washed in PBS. The slides were secondarily subjected to a pepsin solution for 10 minutes at $37^{\circ} \mathrm{C}$ and quenched in a Glycin solution, before being washed again in PBS. After being fixed in a paraformaldehyde solution for 2 minutes, washes were performed 3 times in PBS. Then, the slides were dehydrated through graded alcohols and air dried. The Cambio Y-paint rabbit probe mix was warmed to $37^{\circ} \mathrm{C}$, and 10 to $15 \mu \mathrm{L}$ was applied to the center of the slides, covered with a glass coverslip, and sealed with rubber cement. After overnight hybridization at $37^{\circ} \mathrm{C}$, the rubber cement was peeled off and the coverslip removed. The slides were then washed 3 times in formamide, 3 times in stringency wash solution, once in a detergent wash solution, 3 times in PBS, and mounted in Mountant (catalog no. 1124-MT-50/1250). The samples were observed under a Zeiss Axioplan 2 fluorescence microscope.

\section{RESULTS}

\section{Clinical Evaluation}

In the control group (group 1), 4 of the 12 rabbits died. Death occurred perioperatively for the first 2 . The other 2 rabbits died at 1.5 months of stent migration and obstruction.

In group 2, 2 rabbits died of whole body irradiation. An average of $9.59 \times 10^{6}$ autologous MSCs was injected. Only 10 rabbits underwent tracheal replacement, which occurred at 3 months (range, 2.5-4 months) after autologous MSC transplantation because of a prolonged neutropenia period. Thrombocytopenia was still present in all rabbits and resulted in moderate intraoperative bleeding. No related death occurred. Two rabbits died of stent migration (at 21 days and 5 months) and one of stent obstruction at 21 days.

In group 3, 2 rabbits died of unknown causes at day 1 and day 8. Complete necropsies eliminated the cell injections as a cause of death. An additional rabbit died of stent migration at 1.5 months.

In the postoperative period, all rabbits experienced an irritating cough. In the case of thick secretions, short antimicrobial therapy (intramuscular enrofloxacin $10 \mathrm{mg} / \mathrm{kg}$, $2 \times 24$ hours) was given. Because rabbit intubation was difficult, and tracheal stent mobilization had to be avoided, no fiberscopic aspiration was performed. Therefore, of the 32 rabbits that underwent tracheal replacement, 6 had stent complications, including obstruction and/or migration despite fixation with nonabsorbable sutures, leading to death in all cases. During the entire follow-up period (18 months), no anastomotic leakage, dehiscence, or stenosis was observed. Most of the life-threatening events occurred at points equivalent to the scheduled follow-up intervals, allowing us to explant the tracheal specimens as expected (at 1, 3, 6, 9, 12, 15, and 18 months). The results are presented in Table 1 .

\section{Pathologic Findings}

The macroscopic and microscopic evaluations were quite similar in all 3 groups. Changes in graft integration and physiology were obvious during the 18-month period. At less than 3 months, the macroscopic examination showed a white, thin graft that could be distinguished from the surrounding trachea. After 3 months, the grafts began to appear more integrated and consistently showed a thickened aspect. By 1 year, the grafts were clearly integrated and thickened in all groups. No obvious differences could be observed macroscopically until 15 months, at which time, macroscopic examination revealed cartilage rings in 2 rabbits in the transplantation group (group 2; Figure 2 and Figures E1 and E2). Contraction up to $40 \%$ (graft length measurement, 1.5 to $2 \mathrm{~cm}$ ) was observed after 3 months in all rabbits, but graft stenosis was not seen under any conditions when the stent was in good position. 
TABLE 1. Complications and follow-up

\begin{tabular}{|c|c|c|c|}
\hline Animal no. & Death or euthanasia & Complications & Follow-up \\
\hline \multicolumn{4}{|l|}{ Group 1} \\
\hline 1 & Death & Perioperatively & - \\
\hline 2 & Death & Perioperatively & - \\
\hline 3 & Death & Stent migration & $1.5 \mathrm{mo}$ \\
\hline 4 & Death & Stent obstruction & $1.5 \mathrm{mo}$ \\
\hline 5 & Euthanasia & - & $1 \mathrm{mo}$ \\
\hline 6 & Euthanasia & - & $3 \mathrm{mo}$ \\
\hline 7 & Euthanasia & - & $3 \mathrm{mo}$ \\
\hline 8 & Euthanasia & - & $5 \mathrm{mo}$ \\
\hline 9 & Euthanasia & - & $6 \mathrm{mo}$ \\
\hline 10 & Euthanasia & - & $12 \mathrm{mo}$ \\
\hline 11 & Euthanasia & - & $12 \mathrm{mo}$ \\
\hline 12 & Euthanasia & - & $18 \mathrm{mo}$ \\
\hline \multicolumn{4}{|l|}{ Group 2} \\
\hline 1 & Death & Whole body irradiation & - \\
\hline 2 & Death & Whole body irradiation & - \\
\hline 3 & Death & Stent migration & $21 \mathrm{~d}$ \\
\hline 4 & Death & Stent obstruction & $21 \mathrm{~d}$ \\
\hline 5 & Death & Stent migration & $5 \mathrm{mo}$ \\
\hline 6 & Euthanasia & - & $1 \mathrm{mo}$ \\
\hline 7 & Euthanasia & - & $1 \mathrm{mo}$ \\
\hline 8 & Euthanasia & - & $3 \mathrm{mo}$ \\
\hline 9 & Euthanasia & - & $6 \mathrm{mo}$ \\
\hline 10 & Euthanasia & - & $12 \mathrm{mo}$ \\
\hline 11 & Euthanasia & - & $15 \mathrm{mo}$ \\
\hline 12 & Euthanasia & - & $15 \mathrm{mo}$ \\
\hline \multicolumn{4}{|l|}{ Group 3} \\
\hline 1 & Death & Unknown & $1 \mathrm{~d}$ \\
\hline 2 & Death & Unknown & $8 \mathrm{~d}$ \\
\hline 3 & Death & Stent migration & $1.5 \mathrm{mo}$ \\
\hline 4 & Euthanasia & - & $1 \mathrm{mo}$ \\
\hline 5 & Euthanasia & - & $3 \mathrm{mo}$ \\
\hline 6 & Euthanasia & - & $3 \mathrm{mo}$ \\
\hline 7 & Euthanasia & - & $6 \mathrm{mo}$ \\
\hline 8 & Euthanasia & - & $6 \mathrm{mo}$ \\
\hline 9 & Euthanasia & - & $9 \mathrm{mo}$ \\
\hline 10 & Euthanasia & - & $15 \mathrm{mo}$ \\
\hline 11 & Euthanasia & - & $15 \mathrm{mo}$ \\
\hline
\end{tabular}

Group 1, tracheal replacement alone ( $\mathrm{n}=12$ ); group 2, autologous green fluorescent protein-labeled mesenchymal stem cell transplantation and tracheal replacement $(\mathrm{n}=12)$; group 3 , tracheal replacement and autologous green fluorescent proteinlabeled mesenchymal stem cell injections $(\mathrm{n}=12)$.

Microscopically, aortic tissue in the trachea location was remodeled. Persistence of elastic fibers was present at all stages associated with moderate inflammatory infiltrate. By 3 months, an intact epithelial layer could be visualized throughout the graft. In both the control and MSC injection groups, organized collagenous and connective tissue could be found primarily at the edges of the remodeled tissue. Evidence was seen of nascent cartilage island formation at the anastomoses of the graft in close proximity to cartilage from the recipient but obviously within the graft, as evidenced by the retained elastic fibers present from the aorta (Figure 3). Secretory cells, basal cells, and glandular structures were not fully restored in the graft (Figures E3 and E4).

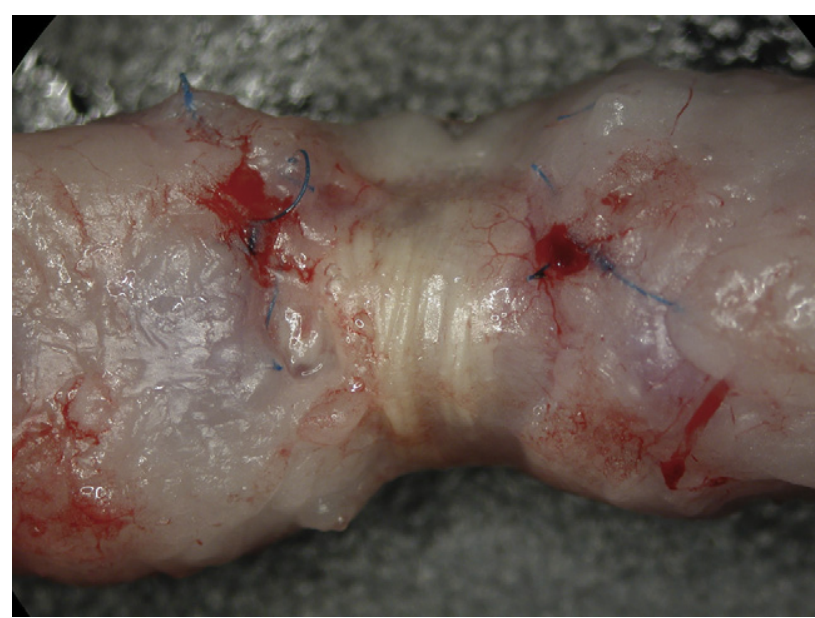

FIGURE 2. Macroscopic examination at 15 months after transplantation group showing moderate retraction and "rings" over the outer surface of graft.

Cell contribution to graft. GFP-positive MSC contribution to structures within the allograft either after bone marrow transplantation of the labeled MSCs or after intravenous injection of cells after aortic allografting was evaluated by fluorescence in situ hybridization for EFGFP. MSC migration or homing to the graft was evident throughout the evaluation period from as early as 21 days through the end of the study period.

EF-GFP epithelial cells were present in rabbits receiving GFP-labeled MSCs by either bone marrow transplantation (Figure 4, A) or intravenous injection (Figure 4, E). Most epithelial cells were GFP-positive in the rabbits receiving a transplant, with EF-GFP cells moderately detected after injection of labeled cells. With increased time, areas of mucociliary differentiation could be seen, primarily at the edges of the remodeled tissue growing toward the middle of the graft, and these differentiated areas were GFP-positive. Positive cells could be seen through the connective tissue in the graft depth (Figure 4, B). Cartilage positivity was moderate and mostly located in the activating border. This detection was confirmed at 6 (Figure 4,C) and 9 (Figure 4,D) months in the injected group (Figure E5).

Hybridization in situ (fluorescent in situ hybridization) for chromosome $Y$. The presence of the $\mathrm{Y}$ chromosome was identified in the epithelium layer coming from the host recipient and growing toward the middle of the graft. The underlying organized fibrous tissue was also positive for the $\mathrm{Y}$ chromosome at 6 and 9 months, showing cell invasion from the host trachea (Figure 5). However, no positive $Y$ detection was observed in the cartilage (Figure E6).

\section{DISCUSSION}

The management of tracheal defects for which primary end-to-end anastomosis cannot be performed remains a clinical challenge. To date, the use of tissue flaps, autografts, 


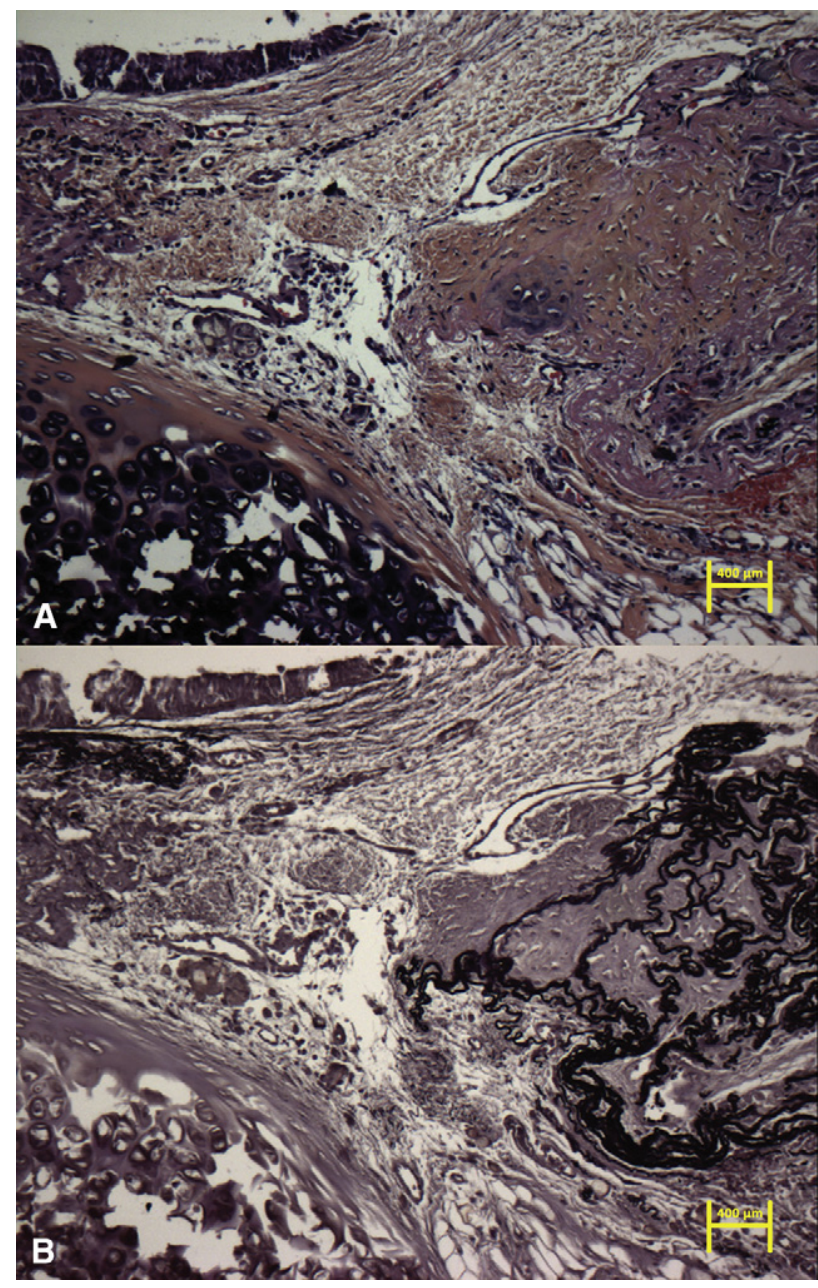

FIGURE 3. Graft at 3 months from injection group. A, Hematoxylineosin-saffron stain (original magnification $\times 10$ ) showing anastomosis localization with epithelial regeneration and new cartilage in formation. $\mathrm{B}$, Orcein stain (original magnification $\times 10$ ) showing elastic fibers within the cartilage island.

allografts, prosthetic materials, stents, or combination of these methods has met with limited clinical significance owing to a multitude of complications, such as great vessels erosion, infection, and necrosis. ${ }^{1,2}$ Even if emerging tissue engineering technologies offer new solutions in the future, a tissue-engineered airway could not be considered a widely applicable clinical treatment. Successful cases have been reported in adults and infants ${ }^{11,12}$; however, for patients requiring treatment now, the aortic allograft remains 1 of the best options. ${ }^{3}$ The results obtained from different animals models (sheep, pig, rabbit, and dog) have been deemed promising enough to be performed on humans, ${ }^{13}$ although the mechanisms of tracheal regeneration remain unclear. Stem cells can be found in multiple organs. ${ }^{14,15}$ Moreover, MSCs reside in virtually all postnatal organs and tissues. ${ }^{16}$ These cells act as a reservoir of undifferentiated cells to supply cellular demands of the tissue, acquiring local phenotypic characteristics. When necessary and after signals from the microenvironment, they give rise to committed progenitors that differentiate and integrate into the tissue. ${ }^{16}$ To explain tracheal regeneration, some reports have suggested the presence of stem cell "niches" able to give rise to a complete mucociliary epithelium after tracheal injury. ${ }^{17}$ However, no report has been published of a specific stem cell isolated in the trachea and leading to cartilage regeneration. From our previous work, ${ }^{7-9}$ we hypothesized that activation of the recipient's multipotent MSCs triggered by environmental signals would result in colonization of the graft and regeneration of new trachea. Bone marrow MSCs constitute an ideal source for cell transplantation and tissue engineering. Complete engraftment, mobilization, and detection of labeled MSCs could have been negative, because many parameters need to be controlled. Therefore, we included the MSC injection group in our study and tested for circulating progenitors. On the basis of the MSC circulating theory, we hypothesized that the injured rabbits would use the circulating MSCs, avoiding bone marrow mobilization. Giving high pools of GFP-labeled MSCs, we increased our chances that these cells would migrate inside the graft. Covering of the anastomotic line by specialized respiratory epithelium, derived from overgrowth of adjacent normal cells with a resultant functional intraluminal lining, represents the optimal outcome after any surgical procedure on the airway. Some investigators have shown that migration, proliferation, and differentiation of basal and secretory cells into ciliated cells leads to epithelial regeneration after experimental injury of the tracheal epithelium similar to the epithelial formation observed during the fetal stage. ${ }^{18}$ The common hypothesis proposed is the migration of basal and mucus cells into the destroyed area, followed by formation of a mucociliary epithelium after a transitory stage of a metaplastic epithelium.

Transplantation of female aortae into male recipients was intentional, to enable later assessment of the graft for the presence of the SRY gene. Positive SRY gene detection serves as evidence of engraftment of cells derived from the male recipient. EF-GFP detection showed the presence of differentiated labeled cells originating from labeled MSCs in the epithelium and connective tissue. In contrast to some investigators, ${ }^{19}$ we found that bone marrowderived MSCs differentiated into epithelium of the upper respiratory tract in rabbits. It is now recognized that the epithelium regulates an array of airway functions, including attraction and activation of inflammatory cells, metabolism and clearance of inhaled agents, and regulation of airway smooth muscle function.

We intended to track labeled MSCs in vivo to study cartilage regeneration inside the aortic allograft. However, no mature cartilage was observed inside the graft. It was instead present in islands at the edges of the graft (or anastomoses). 


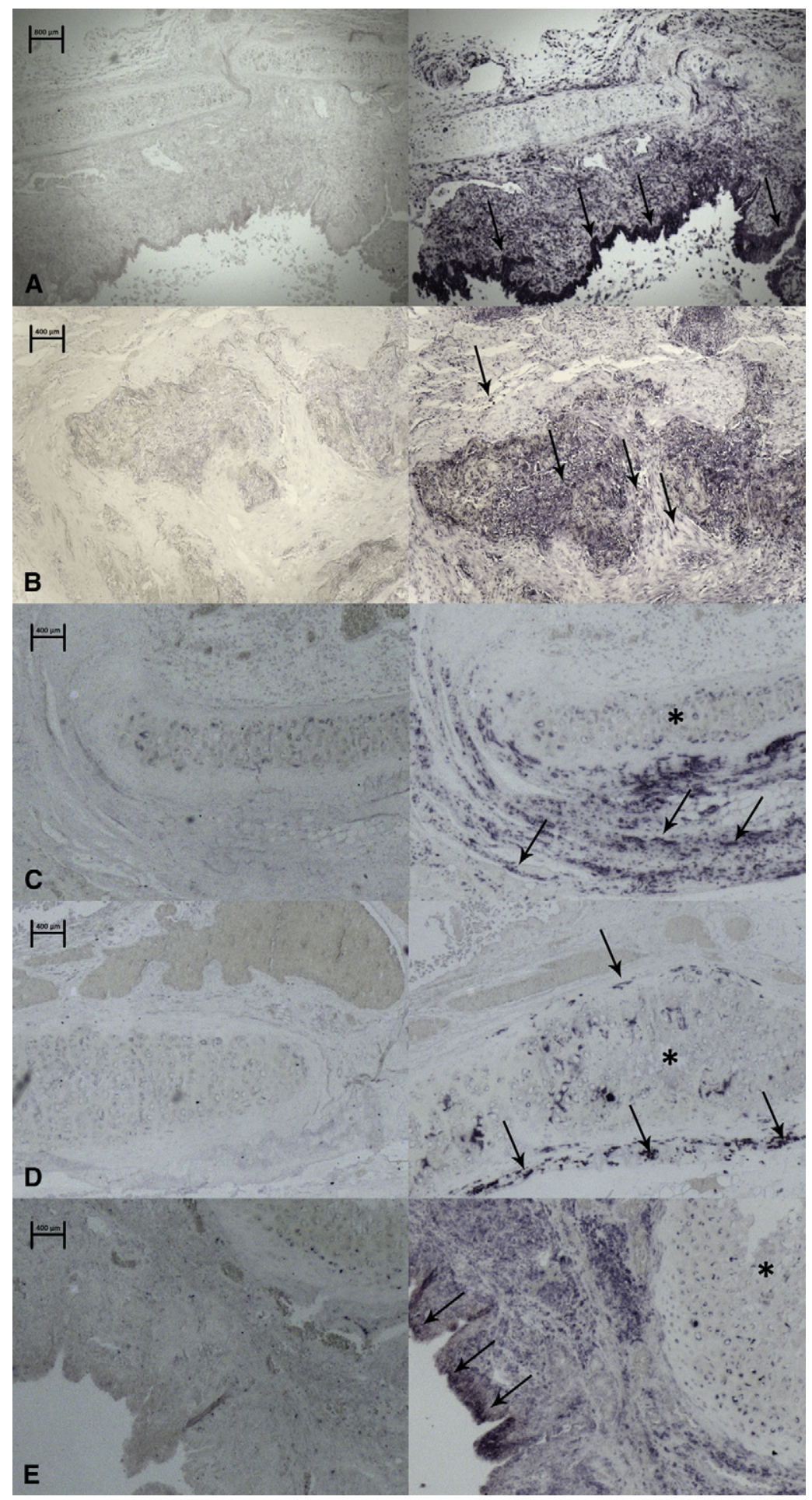

FIGURE 4. Hybridization in situ for the RNA of green fluorescent protein (GFP) for the transplanted and injected groups showing positive detection within the graft and inside the new cartilage. Left, Sense probe detection; right, antisense probe detection. A, Graft at day 21 from transplantation (original magnification $\times 5$ ) showing GFP-positive cells clearly through the epithelial layer (arrows) and at lower levels inside the graft, decreasing with depth. B, Graft at 1.5 months from injection (original magnification $\times 10$ ) showing GFP-positive cells through the connective tissue in graft depth under the epithelial layer. C, Graft at 6 months from injection (original magnification $\times 10$ ) showing GFP-positive cells in the active border (arrows) of recipient cartilage (asterisk) near the anastomosis. D, Graft at 9 months from injection (original magnification $\times 10$ ) showing GFP-positive cells in the active border (arrows) of cartilage of recipient cartilage (asterisk) near the anastomosis. E, Graft at 15 months from injection (original magnification $\times 10$ ) showing GFP-positive cells clearly through the epithelial layer (arrows) and at lower levels inside the graft, decreasing with depth near cartilage (asterisk). 

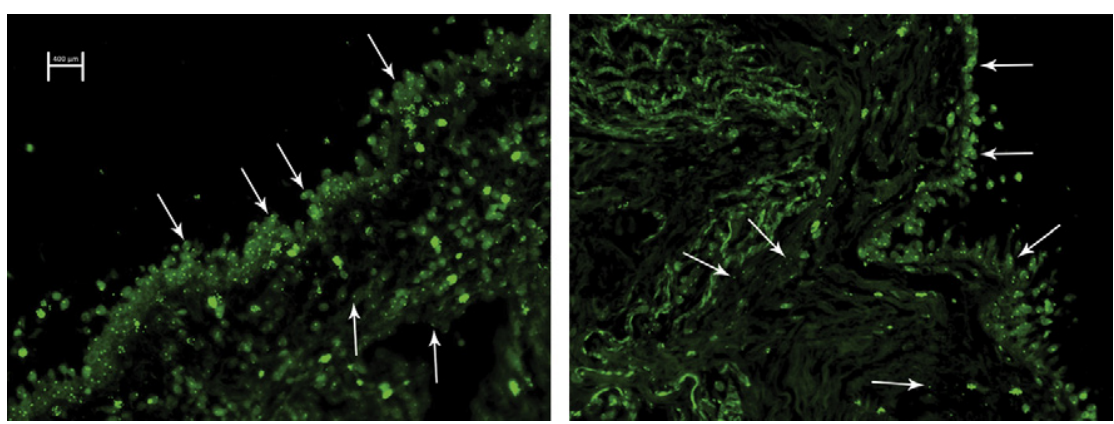

FIGURE 5. Hybridization in situ for the $\mathrm{Y}$ chromosome for graft at Left, 6 and Right, 9 months from injection (group 2; original magnification $\times 10$ ). Positive epithelial cells for the Y chromosome (arrows) can be clearly seen, as well as positive cells inside the graft. (Labeling appears as a small white spot inside each cell.)

These findings raise the question of why the aortic allograft did not transform into normal tracheal tissue in our rabbit model, although the procedure was successful in pig and, even more so, in sheep models. Several possibilities exist. First, a species difference exists in the aortic allograft. For example, the aortic graft is thinner in the rabbit, and it is possible that the closer orientation of the elastic fibers does not permit cell invasion to occur. Second, gender could have played a role. Sexual dimorphism clearly influences the function of various stem cell types throughout the body. ${ }^{20-22}$ Gender dimorphisms exist in the pathogenesis of a variety of cardiovascular, cardiopulmonary, neurodegenerative, and endocrine disorders. Recent studies have reported the presence of estrogen and testosterone receptors on stem cells, suggesting that estrogens and testosterone might modify the function of these cells. ${ }^{20,21}$ Moreover, sex hormones seem to play an important role in the modulation of immune/inflammatory responses, which alter cell mobilization, recruitment, and engraftment. ${ }^{22}$ Pig and rabbit experiments in which the results were less positive were performed on male animals, but the sheep protocols were conducted on juvenile female animals. Another possibility is that graft function drives maturation. In the smaller animal model (rabbit), the grafts were less patent, as evidenced by the thick secretions, coughing, and an inability to aspirate. This decreased functionality could account for the decreased maturation in that biomimetic environments have been shown to drive cell phenotype and function. ${ }^{23}$

Stem cell-based therapies could be very expensive to fully develop if they used autologous cells, because it would be necessary to obtain a biopsy from the patient, expand the cells in culture, perform the required testing, and store cells before administering the therapy. An alternative approach is the use of allogenic stem cells. Although MSCs represent a very small fraction of the total population of nucleated cells in the marrow, they can be isolated and expanded with high efficiency. The use of allogenic MSCs has many advantages, including that the donor can be chosen in advance, qualified, tested for the absence of different disease organisms, and the MSCs prepared can be made available in an off-the-shelf product when needed. Moreover, evidence has shown that MSCs are hypoimmunogenic, permitting the use of an unmatched donor, which has broad implications in terms of allogenic therapy. ${ }^{24} \mathrm{Ad}-$ ditionally, several reports have described the clinical use of allogenic donor-mismatched cells, with little evidence of host immune rejection. ${ }^{25}$ Because stent complications can easily be treated in human care, the mitigated results from the rabbit model should not be viewed as a limitation for clinical application. MSC involvement offers new perspectives to accelerate the tracheal regenerative process. Future studies using collaborative techniques (biology, tissue engineering, and biomaterials) will be based on matrix components to optimize the aortic allograft, cell mobilization and homing to recruit autologous stem cells in the host earlier in the regenerative process, and biomaterial technologies to achieve functional and well-tolerated tracheal stents.

Three limitations need to be acknowledged regarding the present study. The first limitation concerns the model. In contrast to the sheep and pig models, cartilage regeneration is delayed in the rabbit model and could have impaired the results. The second limitation was the small number of rabbits at each point, which prevented us from giving definitive conclusions on the tracheal regeneration process. The third limitation concerns a technical problem: the impossibility of placing the probe inside the cartilaginous matrix, leading us to report negative results for $\mathrm{Y}$ chromosome detection.

The authors thank Tanya Feldberg and Gabriel Caron for their assistance (T. Felberg performed the cell culture and G. Caron, the animal follow-up and histologic staining). The authors thank Dr Xiaobing Yu for providing the EF-GFP construct, Mr Bruno Ferreyrol for the silicone stents (Novatech, La Ciotat, France), and Helen Baldomero (Swiss National Transplant Registry/Basel) for the bone marrow transplantation protocol. Finally, the authors are grateful to Anne Flourens and Suzanne Grindle for their technical assistance.

\section{References}

1. Kucera KA, Doss AE, Dunn SS, Clemson LA, Zwischenberger JB. Tracheal replacements: part 1. Asaio J. 2007;53:497-505. 
2. Doss AE, Dunn SS, Kucera KA, Clemson LA, Zwischenberger JB. Tracheal replacements: Part 2. Asaio J. 2007;53:631-9.

3. Martinod E. Airway transplantation using aortic allografts: a "hot topic." Eur J Cardiothorac Surg. 2012;41:1409-10.

4. Bader A, Macchiarini P. Moving towards in situ tracheal regeneration: the bionic tissue engineered transplantation approach. J Cell Mol Med. 2010;14: 1877-89.

5. Martinod E, Zegdi R, Zakine G, Aupecle B, Fornes P, D'Audiffret A, et al. A novel approach to tracheal replacement: the use of an aortic graft. J Thorac Cardiovasc Surg. 2001;122:197-8.

6. Martinod E, Seguin A, Pfeuty K, Fornes P, Kambouchner M, Azorin JF, et al. Long-term evaluation of the replacement of the trachea with an autologous aortic graft. Ann Thorac Surg. 2003;75:1572-8

7. Seguin A, Radu D, Holder-Espinasse M, Fialaire-Legendre A, DuterqueCoquillaud M, et al. Tracheal replacement with cryopreserved, decellularized, or glutaraldehyde-treated aortic allografts. Ann Thorac Surg. 2009;87:861-7.

8. Jaillard S, Holder-Espinasse M, Hubert T, Copin MC, Duterque-Coquillaud M, Wurtz A, et al. Tracheal replacement by allogenic aorta in the pig. Chest. 2006;130:1397-404.

9. Makris D, Holder-Espinasse M, Wurtz A, Seguin A, Hubert T, Jaillard S, et al. Tracheal replacement with cryopreserved allogenic aorta. Chest. 2010;137:60-7.

10. Cui Y, Golob J, Kelleher E, Ye Z, Pardoll D, Cheng L. Targeting transgene expression to antigen-presenting cells derived from lentivirus-transduced engrafting human hematopoietic stem/progenitor cells. Blood. 2002;99: 399-408.

11. Jungebluth P, Moll G, Baiguera S, Macchiarini P. Tissue-engineered airway: a regenerative solution. Clin Pharmacol Ther. 2012;91:81-93.

12. Elliott MJ, De Coppi P, Speggiorin S, Roebuck D, Butler CR, Samuel E, et al. Stem-cell-based, tissue engineered tracheal replacement in a child: a 2-year follow-up study. Lancet. 2012;380:994-1000.

13. Wurtz A, Porte H, Conti M, Desbordes J, Copin MC, Azorin J, et al. Tracheal replacement with aortic allografts. $N$ Engl J Med. 2006;355:1938-40.
14. Young HE, Mancini ML, Wright RP, Smith JC, Black AC Jr, Reagan CR, et al. Mesenchymal stem cells reside within the connective tissues of many organs. Dev Dyn. 1995;202:137-44.

15. Sabatini F, Petecchia L, Tavian M, Jodon de Villeroche V, Rossi GA, BroutyBoye D. Human bronchial fibroblasts exhibit a mesenchymal stem cell phenotype and multilineage differentiating potentialities. Lab Invest. 2005;85:962-71.

16. da Silva Meirelles L, Chagastelles PC, Nardi NB. Mesenchymal stem cells reside in virtually all post-natal organs and tissues. J Cell Sci. 2006;119(Pt 11):2204-13.

17. Borthwick DW, Shahbazian M, Krantz QT, Dorin JR, Randell SH. Evidence for stem-cell niches in the tracheal epithelium. Am J Respir Cell Mol Biol. 2001; 24:662-70.

18. Tesfaigzi Y. Processes involved in the repair of injured airway epithelia. Arch Immunol Ther Exp. 2003;51:283-8.

19. Davies JC, Potter M, Bush A, Rosenthal M, Geddes DM, Alton EW. Bone marrow stem cells do not repopulate the healthy upper respiratory tract. Pediatr Pulmonol. 2002;34:251-6.

20. Ray R, Novotny NM, Crisostomo PR, Lahm T, Abarbanell A, Meldrum DR. Sex steroids and stem cell function. Mol Med. 2008;14:493-501.

21. Crisostomo PR, Wang M, Herring CM, Morrell ED, Seshadri P, Meldrum KK, et al. Sex dimorphisms in activated mesenchymal stem cell function. Shock. 2006;26:571-4.

22. Soldano S, Montagna P, Villaggio B, Parodi A, Gianotti G, Sulli A, et al. Endothelin and sex hormones modulate the fibronectin synthesis by cultured human skin scleroderma fibroblasts. Ann Rheum Dis. 2009;68:599-602.

23. Vunjak-Novakovic G, Scadden DT. Biomimetic platforms for human stem cell research. Cell Stem Cell. 2011;8:252-61.

24. Koppula PR, Chelluri LK, Polisetti N, Vemuganti GK. Histocompatibility testing of cultivated human bone marrow stromal cells-a promising step towards pre-clinical screening for allogeneic stem cell therapy. Cell Immunol. 2009; 259:61-5.

25. Le Blanc K, Ringden O. Immunomodulation by mesenchymal stem cells and clinical experience. J Intern Med. 2007;262:509-25. 


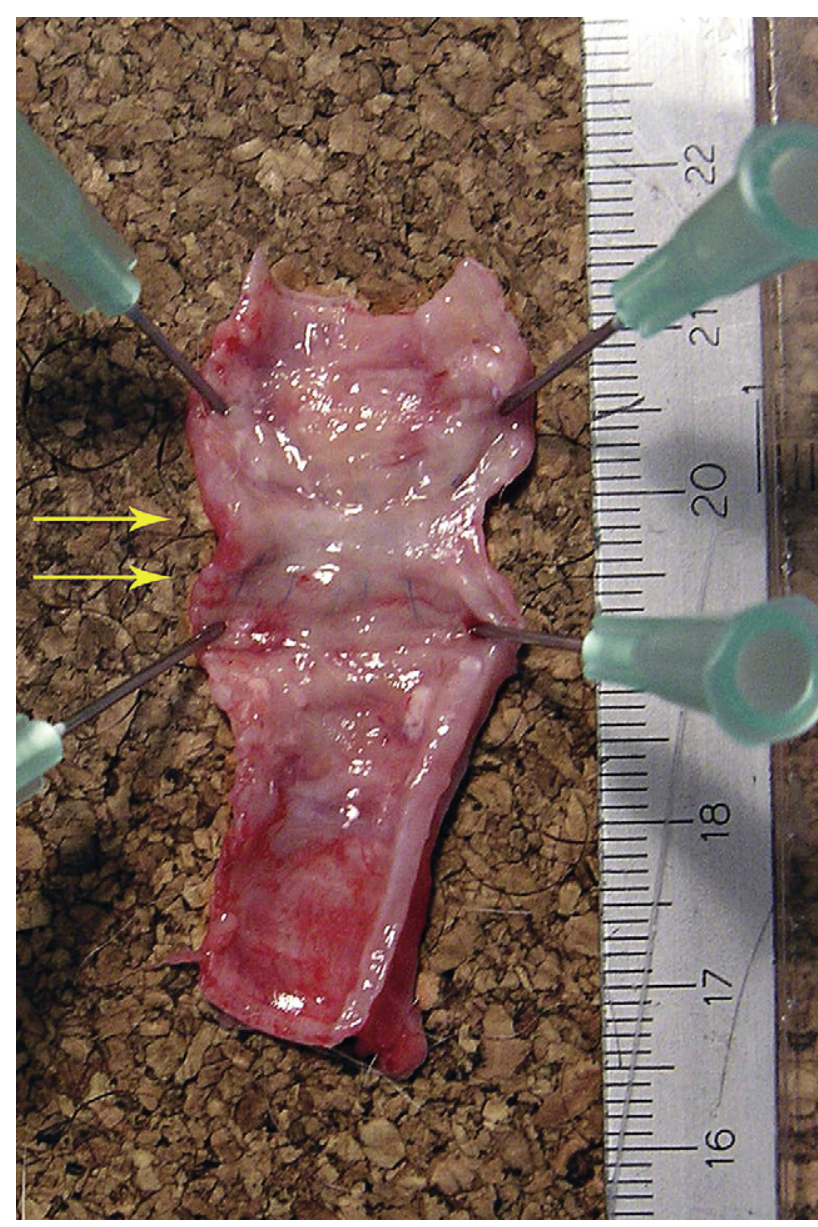

FIGURE E1. Macroscopic examination at 3 months for control group showing moderate retraction and integrated graft. Arrows indicate graft limits.

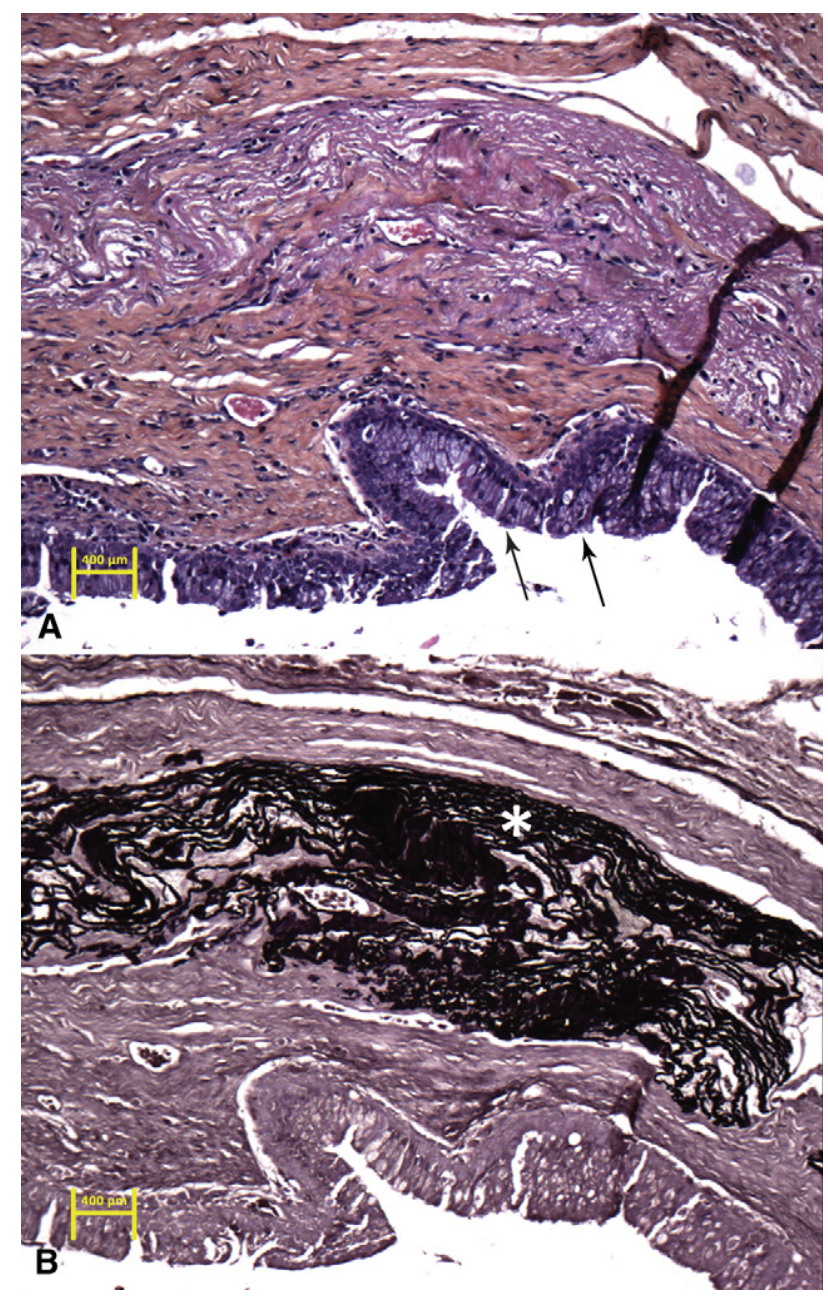

FIGURE E3. Graft at 3 months for control group. A, Hematoxylin-eosinsaffron stain (original magnification $\times 10$ ). Epithelial regeneration (arrows) with elastic fibers present in the deep part of graft. B, Orcein stain (original magnification $\times 10$ ) for elastic fiber detection (asterisk).

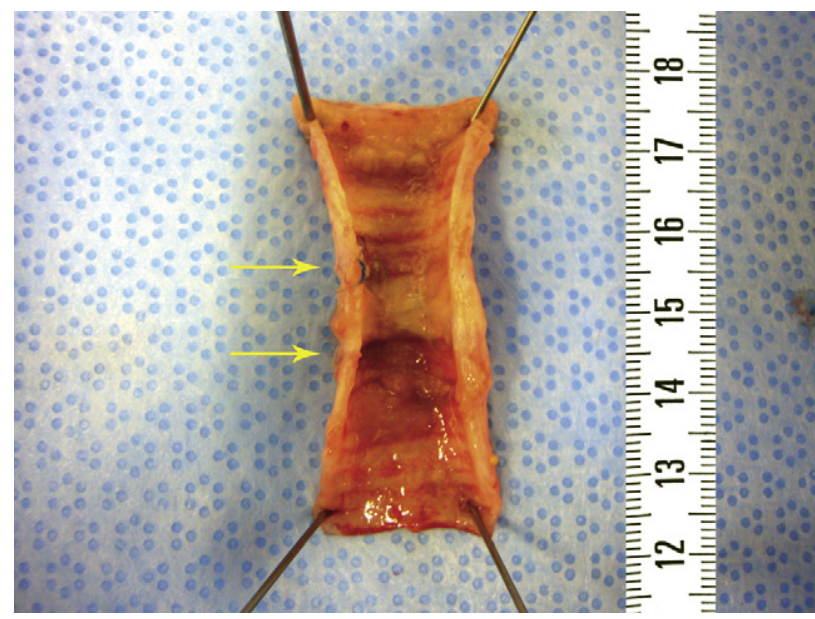

FIGURE E2. Macroscopic examination at 15 months from injection showing moderate retraction and integrated graft. Arrows indicate graft limits. 


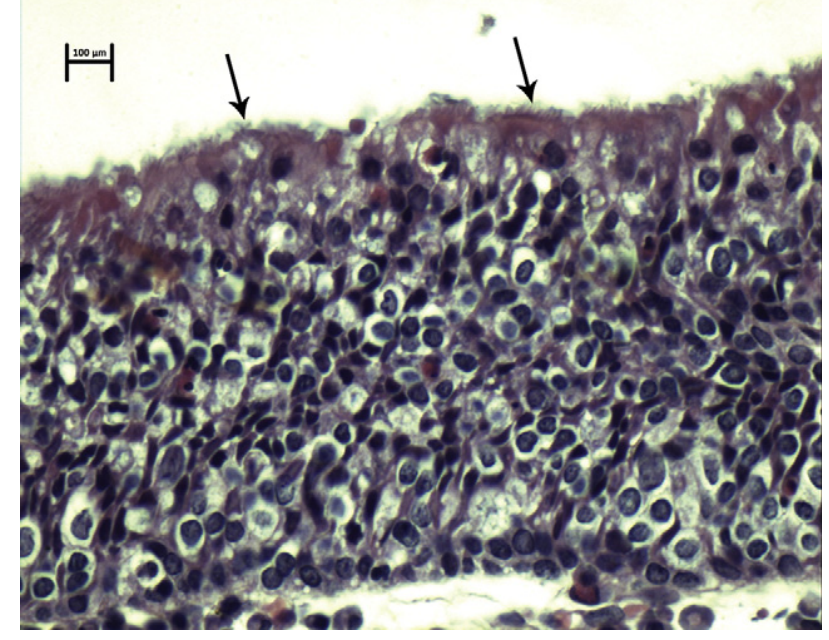

FIGURE E4. Graft at 12 months for control group showing ciliated epithelial regeneration (hematoxylin-eosin-saffron stain, original magnification $\times 40$ ).

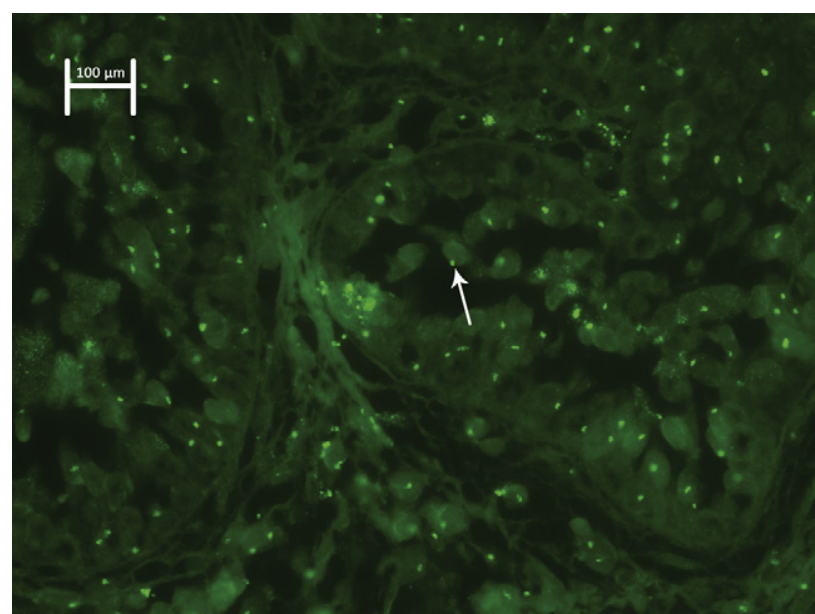

FIGURE E6. Hybridization in situ for the $\mathrm{Y}$ chromosome for graft at 6 months from injection (group 2; original magnification $\times 40$ ). Positive epithelial cells for the $\mathrm{Y}$ chromosome (arrow) and positive cells inside the graft can be clearly seen. (Labeling appears as a small white spot inside each cell.)

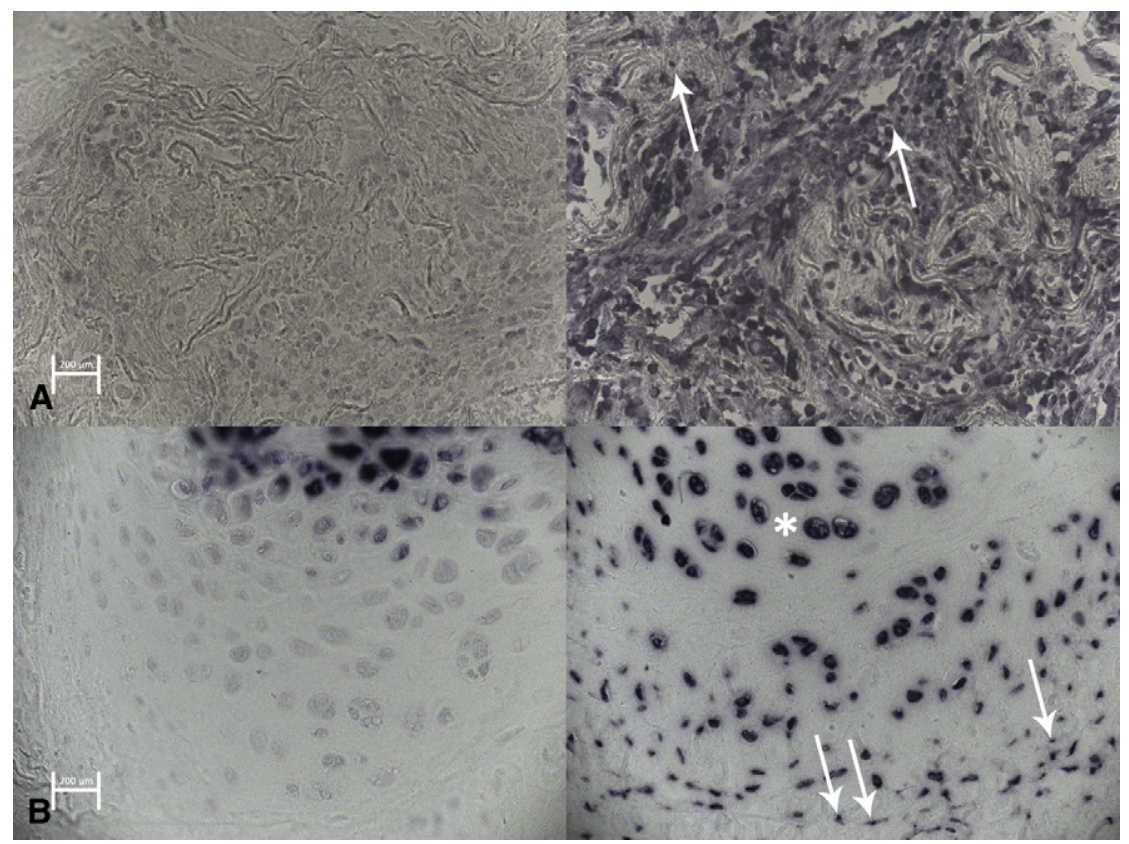

FIGURE E5. Hybridization in situ for RNA of green fluorescent protein (GFP) for the transplanted and injected group showing positive detection within the graft and inside new cartilage. Left, Sense probe detection; right, antisense probe detection. A, Graft at 1.5 months from injection (original magnification $\times 20$ ) showing GFP-positive cells through the connective tissue in the graft depth under epithelial layer. B, Graft at 1.5 months from injection (original magnification $\times 20$ ) showing GFP-positive cells in the active border (arrows) of recipient cartilage (asterisk). 